\title{
OCEANOGRAPHY GOALS
}

$\mathrm{T}_{\mathrm{H}}$

HE GOAL OF Oceanography is to contribute to the Society's goals of disseminating knowledge of oceanography, promoting communication among oceanographers, and providing a forum for building consensus. In this editorial we discuss some challenges we have, some changes we are making, and how you, as members of TOS, can help.

First, of course, we need articles. This includes technical papers like Wally Broecker's explanation of the "conveyer belt"; papers that unify many concepts into one coherent hypothesis, presented in a way that is understandable to all oceanographers. We need more papers like Klaus Wyrtki's reminiscences about his education, which raise issues such as whether students should be required to take courses outside their discipline. This question is just as relevant (and hotly debated) today as it was during his days in graduate school. And we need letters to the editor, or point/counterpoint dialogues, not only about technical issues, but on questions such as the future direction of TOS or of national and international policies affecting oceanography. In this issue Alan Longhurst starts the dialogue. Let us know what you think.

International participation is critical. Our science is one of the most international on Earth, so we must keep a global perspective. Yet, how is this done? Though we have ever-improving electronic communications, it is still difficult to interact at the international level in journals. Alan Longhurst presents some of these issues very clearly in his letter, and he speaks for many others from whom we have heard. We hope that you will consider his comments and give us suggestions for more we can do. One possibility might be a regular column featuring discussion of international aspects of our science.

A new feature of Oceanography appearing in this issue is "The Oceanographer's Toolkit." This section will focus on developments in software, hardware, and other topics such as data sources. The emphasis will be on tools that can be used by a large number of people, rather than the highly specialized ones requiring major hardware resources. Perhaps you know of tools that have been developed privately or are not widely known in our community.

We always welcome good research articles, but Oceanography is not just a technical journal. Technical papers apply to only one of the three goals of the Society, that of disseminating knowledge. There are many other issues on which we can communicate, from educational concerns to public policy. If you have an idea for an article, send us a one-page outline at any time. We will let you know within two weeks if it is appropriate and what the publication schedule would be.

-Larry Atkinson

Constance Sancetta

NOTE: The past few issues of Oceanography have had an unacceptable number of errors. We are aware of the problem and have met with the publishers to change copy editing procedures.

THE OCEANOGRAPHY SOCIETY

1124 Wivenhoe Way Virginia Beach, VA 23454 USA (804) 496-8958; fax: (804) 496-8960 omnet: OCEANOGRAPHY.SOCIETY

OFFICERS

Arnold L. Gordon, President Margaret Leinen, President-Flect Melbourne G. Briscoe, Secretary

William M. Dunstan. Treasurer

COUNSELORS

Richard T. Barber

Stephen E. Calvert

Tommy D. Dickey

Richard Jahnke

Kevin D. Leaman

Charles A. Nittrouer, ex officio

EXECUTIVE DIRECTOR Judi Rhodes

CORPORATE/INSTITUTIONAL SPONSORS Aanderaa Instruments, Inc., Woburn, MA, USA

Chishitsu Chosa-Jo, Ibaraki, Japan GE Astro Space Division Princeton, NJ, USA John G. Shedd Aquarium, Chicago, IL, USA Monterey Bay Aquarium Research Institute, Pacific Grove, CA, USA

National Marine Fisheries Service, Silver Spring, MD, USA

Ober, Kaler, Grimes \& Shriver, Washington, DC, USA

RD Instruments, San Diego, CA, USA

Scripps Institution of Oceanography, La Jolla, CA, USA

Woods Hole Oceanographic Institution Woods Hole, MA, USA

\section{OCEANOGRAPHY}

CO-EDITORS

Larry P. Atkinson

Center for Coastal Physical Oceanography Old Dominion University

Crittenton Hall

Nortolk VA 23529

(516) 683-5558; L.ATKINSON

Internet: atkinson@ccpo.odu.edu

Connie Sancetta

National Science Foundation

Ocean Sciences Division

4201 Wilson Blvd.

Arlington, VA 22203

(703) 306-1586; C. SANCETTA

Internet: csancett@ nsf.gov

ASSOCIATE EDITORS

James W. Ammerman

Department of Oceanography

Texas A\&M University

College Station, TX 77843 USA

(409) 845-5105; J.AMMERMAN

Gregg J. Brunskill

Australian Institute of Marine Science

PMB No. 3, Townsville, M.C.

Queensland 4810, Australia

(77)789211; G.BRUNSKILL 